\title{
Evaluating the Priorities of the Calabria's Coast FLAGs for the Improvement of the Quality of Life of the Fisheries Communities
}

\author{
Alba Distaso, Giuseppa Romeo, and Claudio Marcianò ${ }^{(\bowtie)}$ \\ Mediterranea University of Reggio Calabria, Reggio Calabria, Italy \\ claudio.marciano@unirc.it
}

\begin{abstract}
In this study we attempt to evaluate, using a multi-criteria decision making methodology, the priorities of the directors of the six Fishery Local Action Groups (FLAGs) in Calabria Region coastal areas on some dimensions of quality of life. More specifically, the focus is on the role of the FLAGs as a policy instrument, in the context of the Community Led Local Development (CLLD), aimed at improving the quality of life of the small fisheries communities. The results have highlighted the strengths and meaningful weaknesses of the level of the perception of the quality of life of the areas where the FLAGs operated in the previous EU programming period.
\end{abstract}

Keywords: Fishery Local Action Group - Analytic Hierarchy Process • Community-led local development $\cdot$ Quality of life

\section{Introducing}

Starting from the 80ies, the European Union through the Fishery Common Policy (FCP) has adopted some specific measures aimed at favoring not only the implementation of the sustainability criterion by boosting the reduction of the fishing boats but also at helping the economy of the seafaring communities (Simon 2008). This because one wants to reach "an efficient equilibrium among the firmness of the ichthyic resources, number of the fishery staff, the profitability of the sector and the interest of the consumers" (Simon 2008, p. 55). To such an aim the 1198/06 Reg (E.U.) has introduced new institutional organizational mechanisms able to promote the local development making use of a bottom-up participative approach. The Fishery Local Action Groups (FLAGs) born on the course of the Local Action Groups (LAG), represent the instrument of territorial governance of the ichthyic development involving a plurality of local actors coming from the public, private and no profit spheres. They are appointed to manage the network of the involved parts and play a central role for the sustainable development of the fisheries areas under economic, environmental and social perspectives. Through the local Development Plans (LDP) they adopt policies of development which have to take into account the effective needs and characteristics of the territory (Marcianò and Romeo 2016). 
In this research we have verified the priorities that the FLAGs responsible managers and other privileged observers have on some dimensions of the quality of life (QL). They, representing the local institutions ${ }^{1}$, know the economic and social peculiarities of the fishing sector and may be able to improve the living conditions of the small fishing communities in the region of Calabria.

From the operational point of view, the first step was to translate the concept of QL into measurable dimensions/criteria and sub-dimensions/sub-criteria. Regarding the choice of the dimensions and sub-dimensions, we have considered that QL is an integrative part of sustainability, in the sense that it is inclusive of the environmental, economic, social and cultural dimensions of sustainability. In such way, the level of QL or of well-being is explainable as an expression of the synthesis of the main dimensions of sustainability. The sustainability of development expresses itself in the intergenerational satisfaction of the needs, which does not only include welfare but also well-being, i.e. the set of the "primary goods" (Rawls 1971), the rights and the values. It is well-known that the level of well-being is the result of factors linked to the persons behaviour and their ways of living. When these conditions happen, a certain level of well-being has been reached. With reference to the small communities, we should take into account that the level of QL depends also on the bonds and conditionings linked to the traditions, customs and habits of a specific territory, i.e. to their culture. In order to follow such conception, the reference to the capability approach (CA) becomes necessary (Sen 1985, 1999). This approach allows to assume that, through the concept of the freedom to be and to act both at subjective and social levels, the level of QL may be increased by improving the capabilities of the individuals (Nussbaum and Sen 1993). Another critical issue concerns the reciprocal relationships between QL and sustainable development at local level (Distaso 2008).

The content of the above highlighted arguments will be shown into four sections. The second section is constituted of two paragraphs: in the former the framework of the determinants of QL is analysed, in the latter we examine the methodology used for their weighting; the area of study and the discussion of the results, are the object of the fourth section while some conclusive considerations are outlined in the fifth section.

\footnotetext{
${ }^{1}$ The same European Fishing Fund establishes that, in order to create new sustainable sources of both income and QL (Capgemini et al. 2014a), the most adequate temporal and spatial dimension is the territory. This because it presents common characters and, thus, under certain aspects, it can be considered an homogeneous unity. In such a context, it is relatively easier to implement some policy guidelines able to better understand, according to the bottom-up approach, the needs of the fishing communities. The E.U. regulation by forecasting the Plan of implementation should reply to such requirements and be based on a bottom-up approach. In such a way, it helps the local partners addressing both the short run effects of the common fishing policy and the economic, social and environmental impacts of the progressive exhaustion of the fishing stocks.
} 


\section{Methodology}

\subsection{An Analytical Description of the Dimensions of the QL}

Dealing with an evaluation of intrinsically complex concepts such as QL (Distaso 2007), requires to take into account a multiplicity of factors. We do not intend to make a list but to distinguish into meaningful categories the main elements contributing to create QL. These categories comprehend: 1) the economic dimension; 2) elements expressing the sense of belonging of the individual in the society, which is represented by social capital; 3) the realization of the set of the personal capabilities and the social opportunities, in order to point out that well-being is determined not only by the capability to be (substantially by the personal characteristics or endowment of human capital) but also by the capability to do, i.e. functionings; 4) elements connected to QL, such as the search for a relationship between economy-environment, or between the perception of the vulnerability and capacity of experiential acquisitions able to cope with the risks. The introduction of the concept of resilience allows to reach a dynamic view of well-being and to distinguish between well-being achievement and agency achievement. In order to implement an empirical analysis following the above mentioned theoretical framework, the concept of QL has been shared into five macrocriteria/dimensions to which 27 sub-criteria have been assigned (Table 1).

We have chosen such criteria and sub-criteria because they constitute the most relevant fields of the cultural, social, environmental, economic sustainability beyond concerning issues which are nowadays at the centre of the political and scientific debate. In short, these dimensions regard:

a) Economic variables (income and employment), as main sources of production of wealth. Income is surely an instrument to reach well-being, but it is not an index of well-being. However, if we consider also employment together with the level of income, these economic variables assume a relevant role in the evaluation of the level of QL (ARPA 2015; Le Gallic 2002). Being difficult to know the levels of income in our empirical evaluation, we limit ourselves to obtain information from the possibility of diversifying the activities through the integrated commercialization of the fishing, hand-crafted and agro-industrial products, and the adequacy of the boats aimed at the fishing tourism. With regards to employment, the inquiry is limited to the ascertainment of possible ways of employment in other areas of the economy in order to evaluate the perceived degree of the availability of the employees to the flexibility of the job market.

b) Resilience, here considered not in physical terms but as the capacity of each individual or the group to overcome, resist and survive to a critical situation. The concept of resilience that is based on the shocks which, when they happen, undermine a steady state, and if a system finds itself in a situation of instability, mechanisms bringing it to a new stability are produced (Alinovi et al. 2009). In general, resilience may be defined as a "process linking a set of adaptive capacities to a positive trajectory of functioning and adaptation after a disturbance" (Norris et al. 2008, p. 130). In short, we consider it as an intrinsic ability of a system or the community to resist to the impact of a natural or social event. 
Table 1. Criteria and sub-criteria of the QL

\begin{tabular}{|c|c|}
\hline Criteria & Sub-criteria \\
\hline \multirow[t]{5}{*}{ C1 Income and Employment } & 1.1 Average income \\
\hline & 1.2 Incentives \\
\hline & $\begin{array}{l}1.3 \text { Opportunity of employment in other sectors of } \\
\text { the economy }\end{array}$ \\
\hline & $\begin{array}{l}\text { 1.4 Investing into financial resources for adequacy } \\
\text { of touristic boats }\end{array}$ \\
\hline & 1.5 Integrated marketing \\
\hline \multirow[t]{6}{*}{ C2 Resilience } & $\begin{array}{l}2.1 \text { Overcoming the shocks through institutional } \\
\text { helps }\end{array}$ \\
\hline & $\begin{array}{l}2.2 \text { Overcoming the shocks through helps from } \\
\text { relatives/family }\end{array}$ \\
\hline & $\begin{array}{l}2.3 \text { Overcoming the shocks through an alternative } \\
\text { employment }\end{array}$ \\
\hline & $\begin{array}{l}\text { 2.4 Diversification through direct selling of the } \\
\text { product }\end{array}$ \\
\hline & $\begin{array}{l}2.5 \text { Diversification through ichthyic tourism and } \\
\text { fishing tourism }\end{array}$ \\
\hline & $\begin{array}{l}2.6 \text { Diversification through a reallocation of the } \\
\text { factors of production }\end{array}$ \\
\hline \multirow[t]{7}{*}{ C3 Social Capital } & 3.1 Accountability \\
\hline & 3.2 Trust and reciprocity \\
\hline & 3.3 Trust towards institutions \\
\hline & 3.4 Shared values \\
\hline & 3.5 Decisional processes \\
\hline & 3.6 Efficiency and efficaciousness \\
\hline & 3.7 Knowledge of social capital \\
\hline \multirow[t]{4}{*}{ C4 Social Capabilities } & 4.1 Micro-credit \\
\hline & 4.2 Group work among fishermen \\
\hline & 4.3 Reduction and/or prevention of the conflicts \\
\hline & 4.4 Organization of conferences/workshops \\
\hline \multirow{5}{*}{$\begin{array}{l}\text { C5 Environmental and socio- } \\
\text { economic sustainability }\end{array}$} & 5.1 Reduction of fishing effort \\
\hline & $\begin{array}{l}5.2 \text { Adequate control for conservation of } \\
\text { biodiversity }\end{array}$ \\
\hline & $\begin{array}{l}5.3 \text { Activities for the regeneration of } \\
\text { environmental systems }\end{array}$ \\
\hline & $\begin{array}{l}\text { 5.4 Local, national, international institutional } \\
\text { recommendations }\end{array}$ \\
\hline & 5.5 Market of discards/Landing obligation \\
\hline
\end{tabular}

It deals with identifying not only the global risk but also the set of the capacities of reaction in front of the possibilities to resist to the negative effects of the change. In other words, what counts more is not only the single defensive or offensive reaction 
in front of a risk, but the evaluation of how the individuals manage the risks over the long run. Once evaluating a risk, it is necessary to consider the resilience either as a single act of reaction to a negative event or as a capacity to choose the most adequate strategies to face it. In such a way, since this capacity is founded both on the active and reactive behaviour of the agents, we may deduce that it is the consequence of the capacity of choice of the persons in front of the perceived risks. Then, the derived conceptual framework is based on the relation risks-resiliencecapability. An increase of the capabilities make individuals less vulnerable in case of risks. This means that the concept of vulnerability refers back to the endowment of the capacities of the persons or a social groups, and, thus, to the capabilities. In fact, on the one hand, a low level of resilience indicates that the agents demonstrate a limited disposal to strategic choices and express a will to act in the short run. On the other hand, a higher level of resilience is an index of the possibility of modifying the contingent situation pointing out perspectives of long run. We have to specify that when evaluating the conditions of life, resilience is the contrary of vulnerability since it reduces the probability that the level of well-being decreases owing to a shock. Socio-economic resilience does not only mean a certain degree of resistance to a shock but also a durable preservation of the level of well-being.

c) Social capital or relational capital as an expression of the existing link between the quality of social relationships and individual and collective well-being. It is straightforward that this link, briefly named social quality, contributes to a higher level of QL. Its level is as much as higher as networks of interpersonal relationships and shared values able both to produce social norms, moral obligations and to create associations facilitating the coordination among the members of a community and the collective action, are developed. Several researches have proved that a social environment rich in terms of interpersonal relationships and participatory opportunities creates those specific conditions favourable both for the diffusion of information and a higher level of trust and shared values among the members of the community. Since economic development is strongly stimulated (or prevented) by the structure of social relationships, the economic activity is more dynamic in those situations where social interactions are intense and where reciprocal trust and the observance of rules are customs. These processes find their implementation in social capital as a shape of capital aimed at evaluating the possible individual and collective benefits coming from the social relations among persons. The benefits obtaining from the social relationships are of different nature. It deals with familiar relationships, belonging to associations, good neighbourhood, but also sharing norms or common values translating themselves in trust. Shortly, if the capacity of collaboration in a community increases in order to reach shared rules, we cannot neglect social capital in the evaluation of the QL since it represents the dimension which characterizes social sustainability. For this reason, social capital is also recognized as a relevant analytical category in the dynamics of local development (as for a deepening of this issue, see, Distaso and Distaso 2015).

d) Social capabilities, as a set of capacities through which it is possible to ascertain if individuals are able to act together and cooperate. This in order to face risky situations. The concept of social capability aims at pointing out that belonging to a social group completes individual freedom because this is not limited to the private 
sphere. In such a way, one considers that the individual does not only have private but also social purposes. With regard to the relation between development and freedom, Sen emphasizes that the different types of freedom (positive and negative or freedom to and freedom from) strengthen economic facilities which, on their turn, generate resources for social facilities. Besides, he points out that social opportunities facilitate participation to community life and that there is always a systematic capability of a local community (Sen 1999) ${ }^{2}$. However, we think that capability is a broader and complex concept such as to contain, for instance, human capital and to go beyond the usual conception of the individual capacity to be and to do. According to some authors, such as Stewart (2005) and Ibrahim (2006), the CA analyses the consequences of the embeddedness of the individuals in both relationships and social structures. Accepting this point of view, we may include issues related to identity, culture, life style, beliefs.

The concept on the basis of the CA is to assume that the capabilities of persons are also determined by the conditions of the society and the context in which they live. On this regards, Sen points out that "the circumstances determining different modalities of converting income into the different life styles adopted by the persons are influenced not only by the personal and environmental differences but also by the differences of the social environment and relational perspective" (Sen 2009, p. 264). Among the differences determining the effective life styles, an important role is also assumed by the relational differences, particularly, by "the quality of relations belonging to the community" (Sen 2009, p. 264). Thus, we may define social capabilities as the set of the actions coming from the efficacy of the social interaction. Despite some methodological limitations concerning the passage from the set of indicators of human development to social relationships (Narayan 1999), the concept of social capabilities can be useful in order to define social capital. Indeed, the CA has an heuristic effectiveness due both to the instrumental and intrinsic values which it gives to the relational goods (for a further deepening of this topic, see, Gui 2005; Donati 2011; Donati 2007). Conceiving social capital in a relational perspective means giving value to goods and services which express relationships of social reciprocity. More specifically, investments in social capital have an instrumental value in the cases in which social relationships are established in order to increase the probability to obtain benefits from the interpersonal relationships (Lollo 2011). While, by referring to the intrinsic value of social capital, it means to contribute to improve both the personal and social conditions of well-being. The use of an oxymoron as social capital and social capabilities can be justified (Durston 1998).

By pointing out the implications of social capabilities on the theory of social capital, we can affirm that the comparative analysis of both concepts may lead to overcome both the excessively instrumental idea of social capital and the

\footnotetext{
${ }^{2}$ The importance of the participation of the community life and the impact that the belonging to a social group may represent for the improvement of QL and the increase in the level of well-being go back to the original frame of the CA (Nussbaum 2000; Robeyns 2003, 2005). Sen himself (Drèze and Sen 1995) introduces the concept of social opportunity and he points out that the individual, in order to practice his/her freedom of choice, cannot be considered isolated from the social relationships and out of the institutions offering the possibility of real choices alternative to the personal ones.
} 
individualistic view of the capabilities. In this framework, social relationships can be now considered a structure constituted of social resources (Lin 2001), and social capital is considered as a set of rights allowing each person, beyond his/her interpersonal relationships, to have access to common resources. If such rights are accumulated and transformed in other resources, social capital is an endowment which each individual can mobilize in case of need. Thus, social capital offers an integrated structure "capable of thinking" in terms of access to the resources (Bebbington 1999). Furthermore, the expansion of the foundations of the economic analysis that the approach of capabilities allows, brings new elements to the theory of social capital, such as, for instance, the evaluation of the impact of the social policy not only in terms of the economic advantages but also in terms of functionings ${ }^{3}$. And, if the informative ground of the CA can be extended to include evaluations of value of social structures, social capital may provide a valid structure for the identification of social capabilities.

From what above, we have noticed that social capital and social capabilities, being complementary, are synergic concepts in the sense that they are both a combination of material and immaterial resources available for the individual, since their possession or not determines the effective ability to engage himself/herself in some valuable activities. It should be pointed out that social capital may be considered as an economic reification of capabilities (Lollo 2011). At the empiric evaluation aim, social capabilities may be defined as those individual capabilities through which agents have the possibility to put at their disposal human capital in terms of education, culture, competences, savoir faire, directed at obtaining, through some training a higher level of collective well-being.

e) Environmental and socio-economic sustainability. We refer to that paradigm of sustainable development according to which sustainable development can be explained through the optimal growth expressing the search of an equilibrium between economic growth and environmental degradation" (Siebert 1998, p. 266). In this view, development can be evaluated as the process where the well-being of each individual and the improvement of his/her capabilities are the main aim of the several changes produced. Therefore, sustainable development becomes synonymous of human development (Anand and Sen 2000). Furthermore, accepting the idea of a socially sustainable development, we can state that development is sustainable in social terms if it considers social interactions and their economic, ecological and social implications at the level both of the persons and society (Lehtonen 2004). This because it deals with both improving individual capabilities and social capabilities. The concept of capability integrated with the concept of social sustainable development may lead to the issue of the inter-generational transmission of the capabilities. According to the CA perspective, socially sustainable development guarantees the possibilities of improvement both for the present and future population. Social sustainability means that development should allow, on the one hand, an intergenerational progress of QL and a reinforcement of both individual and social capabilities of

\footnotetext{
${ }^{3}$ Functionings can be defined as those possibilities of implementation which become effective through the capabilities of "doing" and the achievement of the "states of being and doing" (Sen 1985).
} 
well-being, on the other hand, the research of the possibility of a more equal intragenerational distribution of these capabilities (Ballet et al. 2003). We think that this approach is the most adequate one for the empirical investigations, especially in the fishing area where the effects of the interactions between man and environment are among the most tangible ones. An example is given by the consequences deriving from the methods of illegal fishing, by the use of sophisticated instruments aimed at the exploitation of limited resources or overcoming the rate of regeneration of the same resources (Seijo and Salas 2014). Thus, we should consider the interventions of the European Commission mainly aiming at determining the conditions which make economically resilient and ecologically sustainable the development of fishing sector (Capgemini Consulting et al. 2014b).

\subsection{The Weighting Method}

In order to evaluate how the FLAGs directors could give their priorities on the above mentioned dimensions, we have implemented the Analytic Hierarchy Process (AHP) which allows to decompose complex situations in a hierarchical structure articulated in more levels. The AHP, which is a basic approach to decision making, is designed to carry out a pair-wise comparison judgments which are then used to develop the weight vectors (Saaty 1988). This methodology allows the integration of both tangible and intangible criteria and it is useful in those situations where the subjective judgments are a fundamental part of the decisional process. The AHP presents other advantages. Above all, its application reveals itself adequate when performance evaluations have to be expressed. Furthermore, it allows to deals with a composite set of data, some of which, being of qualitative nature, concern opinions of the individuals, in our case of the privileged observers (Adrianto et al. 2005; Romeo and Marcianò 2014). In the cultural context linked to fishing economics, the contradictory information and the inevitable misunderstandings are perceivable also to the external observer since maybe the natural phenomena and the social events are often understood as complex and stochastic concepts. Last, but at not least, such a method may be structured in order to make possible a system founded on collaboration and thus adequate for taking decisions. As regards as the procedure of application, the AHP is articulated into three phases:

1. To the identification of both the aim and the factors to evaluate, it follows the decomposition or hierarchically structure of the decisional problem into levels and sub-levels, each one of these is characterized by determined components;

2. Formulation of the comparative judgements through the pair-wise comparisons between the identified components identified for each level. The crux of the AHP is the determination of the weights specified on the grounds on the subjective judgements which the FLAGs experts have expressed through the questionnaire. Assuming $n$ elements at each level of the identified components, the procedure establishes the building of the square matrix of the two by two comparisons " $\mathrm{A}$ ", in which $\mathrm{w}_{\mathrm{ij}}$ points out the importance of the $\mathrm{i}$ element compared to the $\mathrm{j}$ element, through the attribution of a numerical score which goes back to a semantic (numerical/linguistic) evaluation which, in our case study, varies between 1 and 5 (Saaty 1988). 


\section{$w_{i j}$ value Linguistic Judgments Interpretation}

1 Equal importance; $i$ and $j$ are equally important

2 Moderate importance; $i$ is moderately more important than $\mathrm{j}$

3 Strong importance; $i$ is strongly more important than $\mathrm{j}$

4 Very strong importance; $i$ is definitely more important than $\mathrm{j}$

5 Extreme importance; $i$ is extremely more important than $\mathrm{j}$

For the property of reciprocity, when $\mathrm{w}_{\mathrm{ij}}=\mathrm{k}$ it automatically follows that $\mathrm{w}_{\mathrm{ij}}=1 / \mathrm{k}$, while for the property of symmetry all the elements on the diagonal are equal to 1 , as in the following matrix:

$$
\left[\begin{array}{cccc}
1 & w_{12} & \cdots & w_{1 n} \\
w_{21} & 1 & \cdots & w_{2 n} \\
\cdots & \cdots & \ddots & \cdots \\
w_{n 1} & w_{n 2} & \cdots & 1
\end{array}\right]=\left[\begin{array}{cccc}
1 & 1 / w_{12} & \cdots & 1 / w_{1 n} \\
1 / w_{21} & 1 & \cdots & 1 / w_{2 n} \\
\cdots & \cdots & \ddots & \cdots \\
1 / w_{n 1} & 1 / w_{n 2} & \cdots & 1
\end{array}\right]
$$

The data for pair-wise comparison matrix are collected through survey which has involved mainly the Directors or the Presidents of the six FLAGs of the Calabria region and other privileged observers. The 6 interviews, which were carried out during the period July-August 2015, took place through a direct relationship, i.e. face to face interviews, while only one was through the telephone. In this phase, the five criteria and the 27 sub-criteria, have been submitted to the subjective comparisons of surveyed experts.

3. Numerical determination of the weights through the normalization of the vectors weights identified with the matrix "A". In analytical way, we proceed through the calculation of the geometric mean of the iesima row given by the following equation:

$$
G M_{i}=\prod_{j=1}^{n} w_{i j}
$$

where: $i, j=1,2, \ldots$,

$\mathrm{w}_{\mathrm{ij}}=$ value of the judgement of the value of the matrix

$\mathrm{n}=$ number dimension of the A matrix

The next step is the normalization of the weight vector obtained from the ratio between every single element of the column with the values of the geometric mean and the total of the column, as it is expressed in the following equation:

$$
\bar{W}_{i}=G M_{i} / \sum_{j=1}^{n} G M_{i}
$$


In order to verify the consistency of the obtained results, the auto-value associated to the auto-vector of the maximum coefficient of the matrix of the two by two comparisons "A" which is denominated $\lambda_{\text {max }}$ :

$$
\lambda_{\text {max }}=\bar{W}_{i} * \sum_{j=1}^{n} w_{i j}
$$

which allows to determine the index of consistency given by the following equation, in which $n$ represents the number of the considered criteria:

$$
C I=\lambda_{\max }-n / n-1
$$

By dividing the consistency index per the Random Index (RI), whose value is derived by a pre-constituted table and associated to the number of the $\mathrm{n}$ considered criteria, we obtain the consistency ratio $(\mathrm{RC})$ :

$$
R C=C I / R I
$$

Higher is the value assumed by such an index, minor is the consistency of the subjective judgements which the policy maker expresses. In general, the threshold of tolerance of the CR is of $10 \%$, but values of the $20 \%$ may be tolerated (Saaty 1988).

\section{Results}

\subsection{The Area of Study}

The FLAGs are private-public partnership activated in the Fishery Common Policy, and are constituted of the partnership among representatives of local public institutions, associations of fishing producers, private persons or associates farms of aquaculture and transformation, economic agents dealing with activities regarding the coastal area of relevance. The FLAGs, according to the inter-industrial view of local development, is an instrument born to create a team. This case study has specifically examined the FLAGs operating in Calabria Region (Fig. 1).

Concerning the territorial aspect, the break-down of the Calabrian FLAGs results to be homogeneous and respects the requirements of the Italian Operative planning. The six FLAGs in Calabria Region, representing more the $70 \%$ of the Calabria's seamanship, constitute an important share of the 43 FLAGs nowadays approved at national level. In fact, the FLAGs are strategic instruments of development and their action responds to the needs and crucial priorities in order to overcome the fish chain in Calabria Region. In fact, the IV Fishing European Fund (FEF) forecasts the implementation of some measures for the sustainable development of the fishing areas aimed at:

- strengthening the economic and social well-being of the coastal areas and increase the level of both the fishing products and aquaculture;

- maintaining and increasing the level of employment promoting the diversification connected to the changes in place in the fish sector;

- promoting the quality of the coastal environment. 
In general terms, a substantial differentiation about the complex strategies elaborated by the FLAGs regarding the extremely varied choice among the different Measures, and the incidence of the structural interventions on the territory, in comparison to the promotional and immaterial ones, is found.

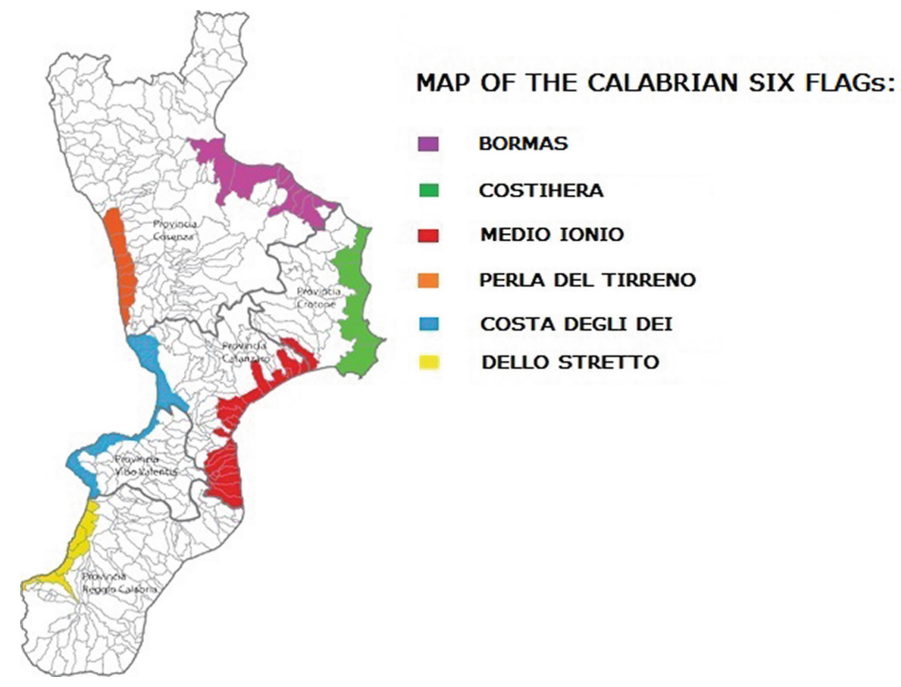

Fig. 1.

\subsection{The Weight of the Dimensions of the Quality of Life}

From the analysis of the obtained results (Fig. 2), it comes out that a relative importance among the macro-criteria is recognized to both the social capabilities (C4) and social capital (C3) with weights respectively equal to 0,25 and to 0,23 . This points out that the directors consider both dimensions as a main priority and that FLAGs pursue the aim to increase the level of the collaborative spirit. Both categories represent the scarcest human resource of the active population not only in the fishing economic sector but also in other sectors. Since the development of capabilities is considered fundamental in order to increase cooperative relationships, the pursue of such an aim is a process whose effects are not immediate having influence on the modalities of formation of the human capital.

As regards the sub-dimensions of social capabilities, such as the participation of conferences and workshops, the directors give a medium importance to it with a relative weight equal to 0,32 and to the group work among fishers with a relative weight equal to 0,27 . With reference to the sub-dimension of social capabilities reduction and/or prevention of conflicts, the value of 0,24 is meaningful, while the directors do not attribute to the micro-credit a high importance. The value equal to 0,17 is the highest among those attributed to the social capital sub-criteria. This means that the FLAGs attribute a remarkable importance to the accountability, i.e. that they adopt and recognize the principles of responsibility, thus undertaking to answer for their 
actions and behaviours. It is well known that trust has a relevant importance in the evaluation of the dimension of social capital. The perception that the privileged observers have with reference to the shared values, i.e. keeping of the civic virtues, such as the capacity to follow the agreements, to be sincere in the social and/or economic relationships, the capacity to place confidence in the others and to responsibly act in the respect of the law- is averagely low in the fishing sector with a value equal to 0,14 . The perception of trust and reciprocity among the actors is as much as low, with a value equal to 0,14 . Thus, in general, the reciprocal trust among the agents is considered to be rather low, even if they give a certain importance to the decisional processes, with a value equal to 0,14 . On this purpose, the same directors of the Costhiera and Perla del Tirreno FLAGs think that the situation could improve if the institution of the Calabria Region would allow a sufficient period of time for the implementation of the Local development Plans (Marcianò and Romeo 2016). It follows the scarce trust also towards the government institutions (the value results equal to 0,12 ). Despite the knowledge about social capital is scarce (the average value is only 0,14 ), although some of the interviewed privileged observers do not know the concept of social capital, they declare to indirectly promote it through specific activities aimed to its increase in value. The values of the sub-criterion of social capital effectiveness and efficacy is averagely higher and is equal to 0,15 . This data indicates that the FLAG role is not always well understood among the population, even if, according to some interviewed stakeholders, they are enough integrated in the territory.

The economic criteria represented by income and employment, whose average weight is equal to 0,21 , result meaningful. A relative importance is attributed to the sub-dimension related to integrated commercialization among fishing, handcrafted, agro-industrial products and touristic services with an average weight equal to 0,28 . In order to boost the integrated marketing, the FLAGs action, which is aimed at the promotion of exhibitions and festivals, may be incisive since they would give a significant contribution to the increase of the added value of the fishing products.

With reference to the fishermen's income (which has an average value equal to 0,21 ), the interpretation is more uncertain as, on the one hand, the FLAGs leaders think that it is sufficient for a dignified life; on the other hand, the interested persons think that it is insufficient. Beyond the fact that the fishermen have a innate reluctance to declare the level of their income, there is the issue about the incentives which are not always promptly supplied. Although the averaged value is equal to 0,18 , we have to point out that, even the small loans to handcrafted fishing are not effectively supplied because, despite the public notices of the Calabria Region to favour fishermen, are considered as bank loans with all the conditions which the banks establish. We can state the same issue regarding the investment of the financial resources for the adequacy of the boats aimed at touristic aims or for employment opportunities in other sectors of the economy.

The weights of the obtained average values are indicative of some evaluations, such as that of the Director of the Costhiera FLAG, according to whom the increase in income due to the fishing-tourism is uncertain since it previously needs an adequacy to the boats and, thus, an adequate investment. In fact, what counts more is a cultural change which a passage from a merely productive activity to a service activity requires. In his turn, the Director of the Bormas FLAG asserts that the fishing-tourism is an 
activity which only the professional fishing can practice and not those who practice the trawling fishing. However, behind these evaluations, a generational issue is emerging, since the new generation does not have any longer the same motivations as the previous generations to exercise an always handed down activity. Furthermore, not even the fact that the norms are becoming more restrictive for the small boats, with the consequence of excessive costs, can explain this change. It is useful to highlight that, in the area of the Stretto, owing to the different conditions due to the beauty of the landscape, the fishing tourism could constitute a source of integration of income (Nicolosi et al. 2016; Romeo and Marcianò 2019; Musolino 2018). With reference to the sub-criterion opportunity to carry out another kind of job, the relative low value explains not only the preference from the fishermen to be employed in the fishing activity since they feel professional but also for the enjoyment of the beauties of the marine milieu.

The average value of sustainability has got a little significance. Most probably the relative low weight attributed to sustainability is explained by the fact that the FLAGs focus more on the dimensions of sustainability of the fisheries communities through the diversification of the activities rather than on the fisheries stocks. With reference to the average value $(0,19)$ of the sub-criterion market of the discards, the FLAGs are involved into the interventions aimed at the rational use of the catch normally discarded in order to improve both the marine habitat and the average incomes of the fishermen. However, regarding the Bormas and Costhiera FLAGs, that minimum quantitative of discards adequate for making the relative market convenient, is not produced. The subcriterion about the capacity of the operators of the fishing sector to consider the advice coming from the local, national, and/or international institutions assumes a minor relevance. This in order to ensure a sustainable management of the fishing areas and its relative ecosystems as well as the reduction of the fishing effort which the FLAGs leaders believe it is a minimal measure to pursue the sustainability in the fishing sector.

With reference to the resilience, the low value indicates that not all the directors give a relevant importance to it. From the interviews it emerges that the perceived level of resilience of the fishermen is very low. The FLAGs could intervene in order to increase the resilience of the fishermen through the diversification of the activities, such as the ichthyic-tourism or the fish tourism. In particular, the mission of the FLAGs is to increase the added value of the downstream productive section (i.e. fishery itself) through the catering service, tourism etc. Also, they do not attribute a relevant importance to the same sub-criterion wide activities of reallocation of the factors of production, such as community, social, recreational services, probably because they think that this activity is not well practised owing also to the inadequate equipment such as the boats, while diversification through the sub-criterion direct selling of the products may be a more efficient way to increase the level of resilience (the weight is equal to 0,27 ). On this purpose, the questions of the schedule regarding the diversification have been formulated on the ground of the Local Development Plan of each FLAG and taking into account the most recent literature (Brugère et al. 2008; Carrà et al. 2014; FARNET 2016). For an analysis of the real conditions in which the agents operate, the issue should go beyond the correct conception of resilience exposed in the dimension (b) of the previous section. We have noticed that the condition of the fisherman is heavily influenced by a controversial character and external to his activity, such as that of the second-hand dealer. The action of this figure should be included in 
that of the intermediation, but operating as a monopolist auctioneer, gains the excellent fishes and he sells it again to the retailers. This condition explains also the economic difficulties of the fishermen owing to the modernization of the boats in case of negative events. Furthermore, according to the President of the Bormas FLAG, if the fishing net or the boats are destroyed, the boats owners although members of the cooperatives, bear the relative costs. This because the cooperatives are formal. Thus, there is possibility for actions aimed at favouring shapes of organization and increase the level of the resilience of the fishermen. Alternatively, fishermen replenish the shocks through loans obtained from the family and relatives, rather than to apply to the external loans. The value of overcoming the shocks through an alternative employment is irrelevant. Vice versa, a way to increase the level of resilience is to boost strategies of diversification of the activities in the fishing sector.

The value inferior to 1 of the standard deviation points out that the privileged observers agree about the evaluations of the different environmental and socioeconomic conditions. The meaning is immediate: the lower is the standard deviation, more the values are close to the average and there is less dispersion of data. In other words, a lower standard deviation indicates similar opinions among the interviewed stakeholders. Among the macro-criteria taken into consideration, the minor weights of the standard deviation equal to 0,05 regard social capital and resilience. Ecological or environmental sustainability follows with a weight of 0,06 . Social capabilities have a weighted medium average of the standard deviation equal to 0,10 . While, regarding the level of income and employment, the value of the standard deviation denotes that the opinions are divergent, the higher is the standard deviation, more different are the opinions.

Lastly, the description above mentioned has allowed to express what has resulted from the inquiry and the elaboration of the information through the building of the Table 2.

Table 2. Main strengths and weaknesses of the level of perception of QL

\begin{tabular}{l|l}
\hline Strengths & Weaknesses \\
\hline - High accountability & - Scarce perception of the presence of the \\
- Presence of a collaborative spirit & shared values \\
- Scarce presence of conflicts & Marginal presence of trust towards institutions \\
- Discrete integration of the stakeholders in & - Scarce trust and reciprocity among actors \\
the territory & - Marginal presence of institutional helps \\
- High perceived level of integrated & - Scarce knowledge of social capital \\
marketing & - Marginal presence of incentives \\
- Discrete perceived level of income & - Inadequacy boats for fishing-tourism \\
- High perceived level of activities of & - Scarce possibility of employment in other \\
regeneration of environmental systems & sectors of the economy \\
- Good possibility of overcoming the & - Excessive control of the small boats \\
shocks through helps from & - Low possibility of considering the \\
relatives/family & recommendations coming from the local, \\
- High level of diversification though the & national and international institutions \\
direct selling of the product & \\
- High tendency towards the market of & \\
discards & \\
\hline
\end{tabular}



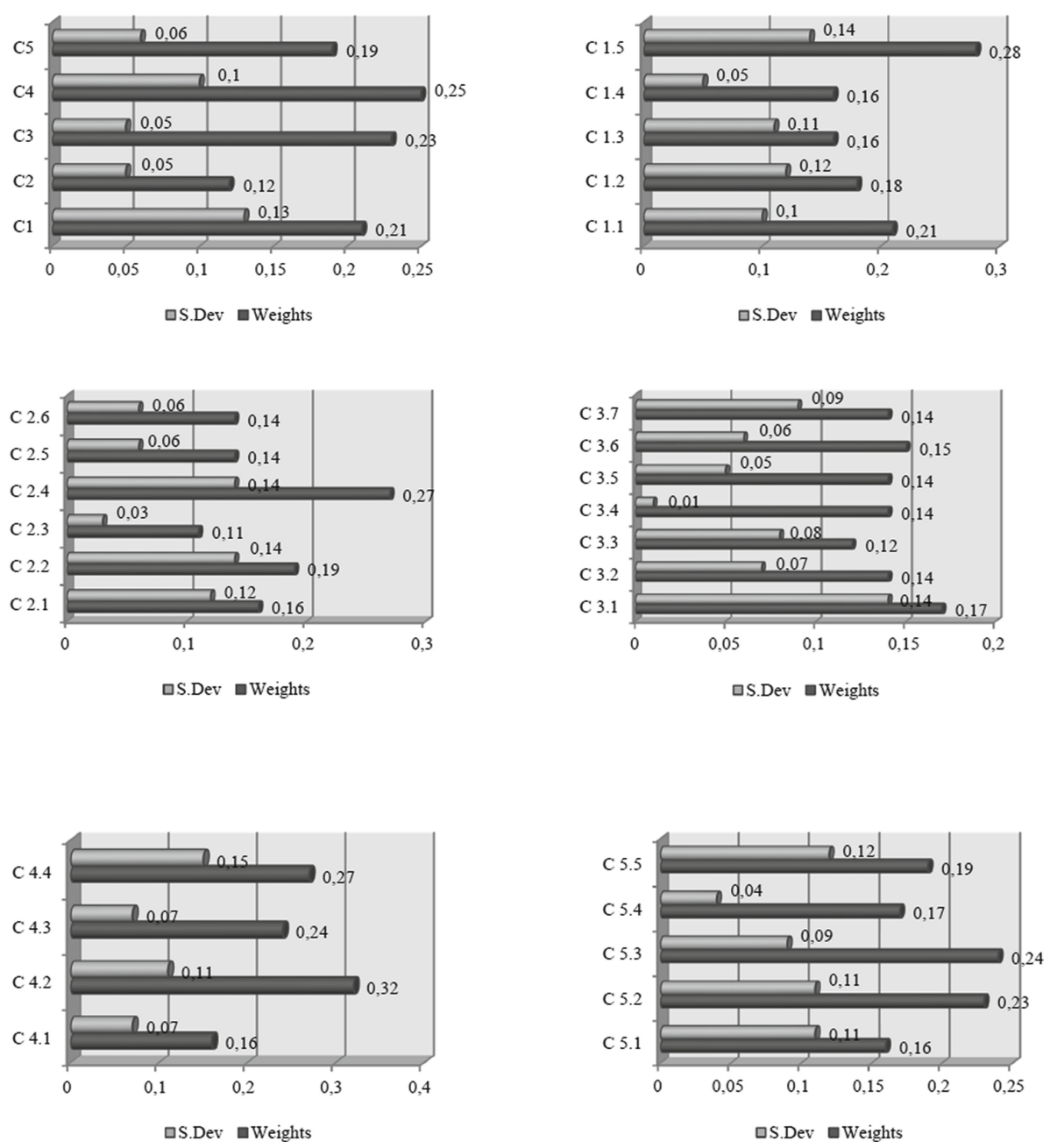

Fig. 2. Average values of the weights of the criteria and sub-criteria of the QL

\section{Concluding Remarks}

In this research we have evaluated the main role of the FLAG as a policy instrument aimed at the improvement of the QL of the small fisheries communities in Calabria Region coastal areas. In this way, by intervening in the field of political, social and environmental economy, the forecasted actions 2014-2020 of the actual planning may be implemented.

From the methodological point of view, since the data of the issues which we have dealt with are of qualitative nature, the multi-criteria analysis has revealed itself an efficacious instrument. To such an aim, we have taken into account five macro-criteria determining QL: income and employment (as more merely economic parameters), 
resilience, social capital, social capabilities, environmental and socio-economic sustainability. These chosen dimensions have been specified into 27 sub-criteria, which are integrated parts of the macro-criteria. Through the employed methodology, the weaknesses and strengths which the coastal areas where the FLAGs operate present, are specified.

The results have highlighted the minor or major importance that the Directors of the FLAGs in Calabria give to the different selected dimensions. For instance, a relative major importance is attributed to the intangible aspects of the QL. This indicates that the FLAGs directors are aware that both social capital and social capabilities are important in those communities especially in a period of crisis of the welfare state. It is necessary that innovative ideas have to be pursued so that well-being may grow in those belonging to the community. Furthermore, the importance attributed to social capital, as the results show, lessens on the ground of the scarce frequency of the interpersonal relationships of trust, and, consequently of shared values. This is a privileged field where the FLAGs could intervene through a major organization of seminars/conferences, team work among fishermen, etc. in order to improve a not very positive situation.

It should be necessary that the FLAGs could give more importance to the resilience, by inducing fishermen toward the diversification of the activities through the direct selling and the marketing of the ichthyic products. Such a kind of diversification gave positive results so far, while lacks are noticed about the activity linked to the fishingtourism owing to the inadequacy of the boats. This activity is efficiently practised only in some areas. The level of efficiency may increase if incentives are given to the handcrafted fishing, if the micro-credit is instituted and if the public institutions are closer to the effective needs of the fishermen.

From our research it emerges that the FLAGs should follow some policy lines of intervention aimed at increasing for instance the level of both social capital and social capabilities if their target is the improvement of the level of quality of life of the fisheries communities. The FLAGs should promote to a greater extent both social capital and social capabilities through cultural meetings, workshops, and activities supporting associationism such as the practice of the micro- credit and by orienting the iter of the started public notices. In such a way, the interpersonal relationships within the small fisheries communities and between them and the FLAGs could be permeated of a higher level of trust. Furthermore, it is necessary to make more efforts in order to let the small fisheries communities comprehend the positive effects deriving from an increase of such capital. This could be easier if all the subjects representatives of the territory and the stakeholders who play a central role in the local context are involved. In fact, we think that the regional institutions should have a relevant position which allows continuity and innovation in the policy guidelines.

Acknowledgments. This study has been published with the contribution of TREnD project (Transition with Resilience for Evolutionary Development), which has received funding from the European Union's Horizon 2020 research and innovation program under the Marie SkłodowskaCurie grant agreement No. 823952. It provides further elaboration of the results obtained within a project supported by the "Stretto" Coast FLAG, Calabria Region - European Fisheries Fund (2007-2013), Priority Axis4: Sustainable Development of Fisheries Areas - Measure 4.1. Strengthening the Competitiveness of Fisheries Areas. 


\section{References}

Adrianto, L., Matsuda, Y., Sakuma, Y.: Assessing local sustainability of fishery system: a multicriteria participatory approach with the case of Yoron Island, Kagoshima prefecture Japan. Mar. Policy 29, 9-23 (2005)

Alinovi, L., Mane, E., Romano, D.: Measuring household resilience to food insecurity: application to Palestinian Households. EC-FAO, Working Paper, pp. 1-39 (2009)

Anand, S., Sen, A.K.: Human development and economic sustainability. World Dev. 12, 20292049 (2000)

ARPA: La concezione del "progresso" e del "benessere" secondo l' OCSE nel progetto "Better Life" (2015). https://www.arpa.piemonte.it/approfondimenti/temi-ambientali/ambiente-esalute/prevenzione-e-previsione-dei-rischi-sanitari/vis/documentazione/progetto-better-lifeocse/le-dimensioni-e-gli-indicatori-del-benessere-dell2019ocse-nel-progetto-201cbetterlife201d

Ballet, J., Dubois, J.L., Mahieu, F.R.: Relating capability and sustainability: the socially sustainable development. Paper Presented for the 3rd Conference on the Capability Approach, University of Pavia, 6th-9th September (2003)

Bebbington, A.: Capitals and capability: a framework for analysing peasant viability. Rural livelihoods and poverty. World Dev. 27, 2021-2044 (1999)

Brugère, C., Holvoet, K., Allison, E.H.: Livelihood diversification in coastal and inland fishing communities: misconceptions, evidence and implications for fisheries management. Working Paper, Sustainable Fisheries Livelihoods Programme (SFLP), Rome, FAO/DFID (2008). http://www.fao.org/fishery/docs/DOCUMENT/sflp/wp/diversification_june2008.pdf

Capgemini Consulting, Wageningen University \& Research, Ramboll: Executive Summary, Study on the Implementation of Axis 4 of the European Fishery Fund, MARE/2011/01 (2014a). https://ec.europa.eu/fisheries/sites/fisheries/files/axis-4-executive-summary_en.pdf

Capgemini Consulting, Wageningen University \& Research, Ramboll: Final Report, Study on the implementation of Axìs 4 of the European Fshery Fund, MARE/2011/01 (2014b). https:// ec.europa.eu/fisheries/sites/fisheries/files/axis-4-final-report_en.pdf

Carrà, G., Peri, I., Vindigni, G.A.: Diversification strategies for sustaining small scale fisheries activities. A multidimensional integrated approach. Rivista di Studi sulla Sostenibilità 1, 7999 (2014)

Distaso, A.: Well-being and/or quality of life in E.U. countries through a multidimensional index of sustainability. Ecol. Econ. 64(1), 163-180 (2007)

Distaso, A.: Local sustainable development and well-being/quality of life. An application of the capability approach at regional level. Rassegna Economica LXX, 287-322 (2008)

Distaso, A., Distaso, M.: Economics of Social Capital: theoretical and empirical approaches. The case study of the Basilicata Region. In: Proceedings LI Convegno SIDEA, 18-20 Settembre, pp. 1-11 (2015)

Donati, P. (ed.): Il capitale sociale. L'approccio relazionale. Sociologia e Politiche Sociali, no. 1, pp. 9-39 (2007)

Donati, P.: Beni relazionali e capitale sociale. In: Donati, P., Solci, R. (eds.) I beni relazionali. Che cosa sono e quali effetti producono. Bollati Boringhieri, Torino, pp. 140-189 (2011)

Drèze, J., Sen, A.: India: Economic Development and Social Opportunity. Oxford University Press, Oxford (1995) 
Durston, J.: Building social capital in rural communities (where it doesn't exist) theoretical and policy implications of peasant Empowerment in Chiquimula, Guatemala. Paper Prepared for Delivery at the 1998 Meeting of the Latin American Studies Association (LASA), Chicago, IL, The Palmer House Hilton, 24-26 September (1998)

FARNET: Results-oriented CLLD in fisheries areas. E. European Commission, DirectorateGeneral for Maritime Affairs and Fisheries, Director-General, May 2016. https://webgate.ec. europa.eu/fpfis/cms/farnet/results-oriented-clld-fisheries-areas-helsinki-finland-24-26

Gui, B.: From transactions to encounters: the joint generation of relational good and conventional goods. In: Gui, B., Sugden, R. (eds.) Economics and Social Interactions, pp. 23-51. Cambridge University Press, Cambridge (2005)

Ibrahim, S.S.: From individual to collective capabilities: the capability approach as a conceptual framework for self-help. J. Hum. Dev. 7, 397-416 (2006)

Le Gallic, B.: Fisheries sustainability indicators. The OECD experience. In: Joint Workshop EEA-EC DG Fisheries-DG Environment on "Tools for Measuring (Integrated) Fisheries Policy Aiming at Sustainable Ecosystem", 28-29 October, Brussels, Belgium. Fisheries Division Directorate for Food, Agriculture and Fisheries, OECD, pp. 1-11 (2002)

Lehtonen, M.: The environmental-social interface of sustainable development: capabilities, social capital, institutions. Ecol. Econ. 49, 199-214 (2004)

Lin, N.: Building a network theory of social capital. In: Lin, N., Cook, K., Burt, R.S. (eds.) Social Capital. Theory and Research. DeGruyter, New York (2001)

Lollo, E.: Social capital and the capability approach: new answers to old problems, 1-14 (2011). http://www.happinesseconomics.net

Marcianò, C., Romeo, G.: Integrated local development in coastal areas: the case of the "Stretto" Coast FLAG in Southern Italy. Procedia Soc. Behav. Sci. 223, 379-385 (2016)

Musolino, D.: Characteristics and effects of twin cities integration: the case of Reggio Calabria and Messina, 'walled cities' in Southern Italy. Reg. Sci. Policy Pract., 1-20 (2018)

Narayan, D.: Bonds and Bridges: Social Capital and Poverty. Poverty Group, PREM, World Bank (1999)

Nicolosi, A., Sapone, N., Cortese, L., Marcianò, C.: Fisheries-related tourism in southern Tyrrhenian coastline. Procedia Soc. Behav. Sci. 223, 416-421 (2016)

Norris, F.H., Stevens, S.P., Pfefferbaum, B., Wyhe, K.F., Pfefferbaum, R.L.: Community resilience as a metaphor, theory, set of capacities and strategies for disaster readiness. Am. J. Community Psychol. 41, 127-150 (2008)

Nussbaum, M.C., Sen, A. (eds.): The Quality of Life. Clarendon Press, Oxford (1993)

Nussbaum, M.C.: Women and Human Development: The Capabilities Approach. Cambridge University Press, Cambridge (2000)

Rawls, J.: A Theory of Justice. Harvard University Press, Cambridge (1971)

Robeyns, I.: Sen's capability approach and gender inequality: selecting relevant capabilities. Fem. Econ. 9, 61-92 (2003)

Robeyns, I.: The capability approach: a theoretical survey. J. Hum. Dev. 6, 93-114 (2005)

Romeo, G., Marcianò, C.: Performance evaluation of rural governance using an integrated AHPVIKOR methodology. In: Zopounidis, C., Kalogeras, N., Mattas, K., van Dijk, G., Baourakis, G. (eds.) Agricultural Cooperative Management and Policy. Book Series Cooperative Management, pp. 109-134. Springer, Cham (2014)

Romeo, G., Marcianò, C.: Evaluating the economic performance of fishing systems using fuzzy multicriteria analysis in a Fishery Local Action Group in South Italy. Fish. Res. 218, 259-268 (2019)

Saaty, T.L.: Mathematical Methods of Operations Research. Dover Publications, New York (1988) 
Seijo, J.C., Salas, S.: The role of capacity building for improving governance of fisheries and conservation of marine ecosystems. In: Garcia, S.M., Rice, J., Charles, A. (eds.) Governance of Marine Fisheries and Biodiversity Conservation. Interaction and Coevolution, pp. 374384. Wiley, Chichester (2014)

Sen, A.K.: Commodities and Capabilities. Elsevier and Reprinted, Amsterdam (1999). Oxford University Press, New Delhi (1985)

Sen, A.K.: Development as Freedom. Knopf, New York (1999)

Sen, A.K.: The Idea of Justice. Penguins Books Ltd., London (2009)

Siebert, H.: Economics of the Environment. Theory and Policy. Springer, Heidelberg (1998)

Simon, F.: Politica economica dell' ambiente e delle risorse naturali nel XIX e XX secolo. Il caso particolare dell' ecosistema marino. In: Cognata, A., Pipitone, V. (eds.) La valutazione delle risorse ambientali. Approcci multidisciplinari al Golfo di Castellamare, Franco Angeli, Milano, pp. 41-60 (2008)

Stewart, F.: Groups and capabilities. J. Hum. Dev. 6, 185-204 (2005)

Open Access This chapter is licensed under the terms of the Creative Commons Attribution 4.0 International License (http://creativecommons.org/licenses/by/4.0/), which permits use, sharing, adaptation, distribution and reproduction in any medium or format, as long as you give appropriate credit to the original author(s) and the source, provide a link to the Creative Commons license and indicate if changes were made.

The images or other third party material in this chapter are included in the chapter's Creative Commons license, unless indicated otherwise in a credit line to the material. If material is not included in the chapter's Creative Commons license and your intended use is not permitted by statutory regulation or exceeds the permitted use, you will need to obtain permission directly from the copyright holder. 